\title{
Review \\ A Review on the Rehabilitation Exoskeletons for the Lower Limbs of the Elderly and the Disabled
}

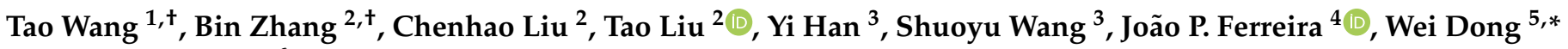 \\ and Xiufeng Zhang ${ }^{6, *}$
}

check for

updates

Citation: Wang, T.; Zhang, B.; Liu, C.; Liu, T.; Han, Y.; Wang, S.; Ferreira, J.P.; Dong, W.; Zhang, X. A Review on the Rehabilitation Exoskeletons for the Lower Limbs of the Elderly and the Disabled. Electronics 2022, 11, 388. https://doi.org/10.3390/

electronics 11030388

Academic Editor: Enzo

Pasquale Scilingo

Received: 11 November 2021

Accepted: 19 January 2022

Published: 27 January 2022

Publisher's Note: MDPI stays neutral with regard to jurisdictional claims in published maps and institutional affiliations.

Copyright: (c) 2022 by the authors. Licensee MDPI, Basel, Switzerland. This article is an open access article distributed under the terms and conditions of the Creative Commons Attribution (CC BY) license (https:// creativecommons.org/licenses/by/ $4.0 /)$.
1 Nanjing Lishui High-Tech Industry Investment Co., Ltd., 288 Qinhuai Avenue, Lishui District, Nanjing 211200, China; twang@zlznzz.com

2 State Key Laboratory of Fluid Power and Mechatronic Systems, School of Mechanical Engineering, Zhejiang University, Hangzhou 310027, China; zjuzhangbin@zju.edu.cn (B.Z.); 12125056@zju.edu.cn (C.L.); liutao@zju.edu.cn (T.L.)

3 Department of Intelligent Mechanical Systems Engineering, Kochi University of Technology, 185 Miyanokuchi, Tosayamada-Cho, Kami 782-8502, Japan; hanyi1719@126.com (Y.H.); wang.shuoyu@kochi-tech.ac.jp (S.W.)

4 Institute of Superior of Engineering of Coimbra, Quinta da Nora, 3030-199 Coimbra, Portugal; ferreira@mail.isec.pt

5 School of Mechatronics Engineering, Harbin Institute of Technology, Harbin 150001, China

6 Key Laboratory of Rehabilitation Technical Aids Technology and System of the Ministry of Civil Affairs, National Research Center for Rehabilitation Technical Aids, Beijing 100176, China

* Correspondence: dongwei@hit.edu.cn (W.D.); zhangxiufeng@hit.edu.cn (X.Z.); Tel.: +86-186-8689-3076 (X.Z.)

+ These authors contributed equally to this work.

\begin{abstract}
Research on the lower limb exoskeleton for rehabilitation have developed rapidly to meet the need of the aging population. The rehabilitation exoskeleton system is a wearable manmachine integrated mechanical device. In recent years, the vigorous development of exoskeletal technology has brought new ideas to the rehabilitation and medical treatment of patients with motion dysfunction, which is expected to help such people complete their daily physiological activities or even reshape their motion function. The rehabilitation exoskeletons conduct assistance based on detecting intention, control algorithm, and high-performance actuators. In this paper, we review rehabilitation exoskeletons from the aspects of the overall design, driving unit, intention perception, compliant control, and efficiency validation. We discussed the complexity and coupling of the manmachine integration system, and we hope to provide a guideline when designing a rehabilitation exoskeleton system for the lower limbs of elderly and disabled patients.
\end{abstract}

Keywords: exoskeleton; intention perception; rehabilitation; medical treatment; efficiency evaluation

\section{Introduction}

At present, there are a large number of people in China who suffer various movement dysfunctions at different levels caused by stroke, spinal cord injury, and aging. It causes a dual physical and mental impact on patients themselves and brings a heavy medical burden to society and family [1]. Statistics from the Disabled Persons' Federation of China showed that the total number of disabled people had exceeded 85 million, accounting for approximately $6 \%$ of the national population, among which about 24 million people were suffering from physical disability [2], which requires care. Stroke is the deadly diseasewith a high mortality and disability rate, which has shown explosive recent growth; $85 \%$ of stroke patients lose their walking ability [3]. Moreover, trauma and degeneration are the main causes of paralysis accompanied by motion and sensory dysfunction. There are 2.5 million people worldwide who have suffered from this disease, and the number has increased to 130 thousand annually [4]. The seventh national census of China shows that the elderly above 60 account for $18.7 \%$ of the population, while the latest forecast of United Nations population data shows that the elderly population in China will approach 
470 million, accounting for more than $30 \%$ of the total population in 2025 . This means that China will become the country with the highest degree of an aging population in the world, bringing severe challenges to the elderly care service system [5].

Elderly or disabled people with lower limb motor dysfunction, who stay in bed or sit for a long time, will gradually develop a series of complications, such as pressure ulcers, muscle atrophy, organ dysfunction, edema, or osteoporosis, which will further worsen the health condition [6]. In order to improve the quality of life of such people, there is already effective auxiliary walking equipment, such as crutches and wheelchairs, but such devices are unintelligent and inconvenient to use [7] for the people who have lost their moving ability. On the other hand, appropriate medical treatment is also an essential procedure, and rehabilitation doctors need to formulate detailed treatment plans according to the patient's condition and complete regular procedures of body exercise training [8]. However, facing such a large number of patients with movement dysfunction, the relevant professional technicians will be in short supply with the aging population. The recovery of patients depends directly on the professional quality and clinical experience of the technicians. The rehabilitation training process will also seriously consume the physical energy of the physician, which is not conducive to improving efficiency and saving costs. To meet the increasing demand, which is combining the professional rehabilitation procedures with daily assistance, exoskeleton technology has drawn increasing attention to achieve intelligent training and evaluation.

The vigorous development of exoskeletal technology has brought new ideas regarding the rehabilitation and medical treatment of patients with motor dysfunction, which is expected to help such people complete their daily physiological activities or even reshape their motion function [9]. To fully understand the efforts on rehabilitation exoskeletons, this paper reviews the published works on rehabilitation exoskeletons from 2003 to 2021 in the Web of Science database [10]. When the papers were reviewed, keywords "rehabilitation exoskeleton" and "lower limb exoskeleton" were combined with "for the disabled" or "for the elderly" to collect the published literature. The keywords search generated more than 136 journal and conference papers related to rehabilitation exoskeletons. Papers not related to the research topic, repetitive articles, and articles related to walking aids for the blind and children's rehabilitation aids were excluded. We selected 96 papers to review the exoskeletons from the point of manufacturing the rehabilitation exoskeletons. Based on their contents, the key points of these papers can be categorized into five aspects: ergonomic design, actuation, perception, control, and validation methods.

The exoskeleton systems were identified as wearable man-machine devices made through anthropomorphic design, providing active assistance to the users according to their motion intention. This is one of the most promising potential technical studies to deal with the problems of disabled care and elderly assistance and rehabilitation [9]. The design of rehabilitation exoskeletons should match the ergonomic principles to guarantee that the system can correspond with the distribution of human joints. To achieve rehabilitation procedures, the structure of the system should be specified, including sensors, actuators, and controllers. Based on our surveyed literature, most exoskeletons were actuated by motors and some artificial actuators such as pneumatic muscles (PMs) [11] and shape memory alloy (SMA) [12] were reviewed. The control methods determined the performance of the exoskeletons conducting assistance and rehabilitation. The control algorithms were set to maintain human-machine interaction and send the precise control commands to drive the actuators to perform corresponding auxiliary actions. Most interaction methods were achieved by feedback control based on detecting the information of the exoskeletons, the users, or the man-machine coupling system. Many behavioural and physiological sensors were introduced into the rehabilitation system to represent the status of the manmachine system, where the behavioural and physiological sensors describe the kinematic features (such as joint angles, velocity, acceleration, etc.) and human physical status (such as heart rate, Electromyogram (EMG), electroencephalogram (EEG), etc.). Whether it is helping patients with daily physiological activities such as walking or performing regular 
rehabilitation training in accordance with the treatment plan, the exoskeleton system could easily and effectively complete the rehabilitation goals. Finally, it is necessary to evaluate the effectiveness of the exoskeleton systems and the performance of the assistance and rehabilitation.

Developed countries represented by the United States, Switzerland, and Canada started to explore the design and application of rehabilitation medical exoskeleton robots very early [13]. So far, a series of commercial products have been developed to meet various needs, which has greatly promoted the research process of exoskeleton technology in helping the elderly and the disabled. During the 11th Five-Year Plan of China, according to the growing demand for domestic social development (especially the elderly and the disabled), rehabilitation robots started as a key research project. In the 12th Five-Year Plan, a further concept was proposed regarding rehabilitation. The 13th Five-Year Plan carried out a continuous special research plan for rehabilitation robots [14]. At present, both universities and institutes have been committed to the research, and a large number of rehabilitation exoskeletons have also emerged [15].

The ergonomic design determined the matching performance of the exoskeletons, which plays a fundamental role to achieve assistance and rehabilitation. The actuators, sensors, and controllers are the basic elements to conduct motion, perception, and control, which are the essential parts of the rehabilitation exoskeletons. The validation methods were designed to confirm the effectiveness of the rehabilitation procedure and the exoskeletons. In this paper, we reviewed the rehabilitation exoskeletons from the aspects of ergonomic design, actuation, perception, control, and validation. We discussed the advantages and limitations of the man-machine interaction systems and stated our considerations of designing and developing the rehabilitation exoskeletons in the future. We hope this paper can provide an overall guideline to design a rehabilitation exoskeleton system. The contributions of this paper include: (1) as a paper dedicated to reviewing the rehabilitation exoskeletons, five aspects are listed to summarize state of the art technologies; (2) the advantages and limitations for every aspect are proposed; (3) the challenges of the ergonomic design, sensor-based motion perception, actuation, and control were discussed. We hope this paper could provide a guideline when designing a rehabilitation exoskeleton system for the lower limbs of the elderly and disabled.

\section{Design of the Rehabilitation Exoskeletons}

Due to the differences in the degree and location of the loss of motor function of the wearer, the structural forms of the exoskeleton helping the elderly can be designed according to the different rehabilitation goals. The unpowered exoskeletons, which do not contain any powered elements (such as a battery, electric motor, etc.), provided a rich experience for the ergonomic design because the matching performance determined the distribution and transmission of the force [16]. There were already several representatives of passive exoskeletons, such as OX, UPRISE, Niudi, and FORTIS [16]. The OX was designed by the Australian Government Department of Defense, and it can transfer two-thirds of the pressure borne by a soldiers' shoulders, spine, and legs to the ground. Mawashi Co. (Quebec, Canada) developed UPRISE transferring $50-80 \%$ of the pressure borne by a soldiers' shoulders to the ground without interfering with normal motion. UPRISE is constructed by using high-strength titanium alloy. Niudi Co. (Chongqing, China), LTD from China proposed a modularized UE that can withstand $70 \mathrm{~kg}$ but weighs only $6 \mathrm{~kg}$. The FORTIS is designed by Lockheed Martin Co. (Bethesda, MD, USA) to help workers carry heavy tools. The unpowered exoskeletons have great potential in the military, industry, rescue fields, etc. The passive exoskeletons were well-bionic designed and constructed by dexterous structure. The ergonomic design of the passive exoskeleton could be referred to as the design of rehabilitation exoskeletons.

The rehabilitation exoskeletons were designed for the elderly and the disabled who have been suffering from moving dysfunction. Compared with the power-enhanced exoskeleton worn for people with normal mobility, the safety and stability of the man- 
machine interaction process must be guaranteed through the special design of the system itself in structure. To achieve this basic requirement, the overall scheme of the existed systems was divided into a platform-based exoskeleton, crutches-based exoskeleton, and self-balanced exoskeleton. The Swiss Locomat [17] and American ALEX III [18] belong to the first type of rehabilitation exoskeleton. The users were equipped with lower limb exoskeletons under the protection of the weight support structure and completed the walking process on the treadmill, which can safely achieve the intensive training of lower limb muscle strength, as shown in Figure 1c,d. The second type of system combines crutches with the exoskeleton. The Israeli ReWalk series [19] introduced the users' upper limbs to maintain stability by using crutches for patients with lower motion dysfunction, as shown in Figure 1b. The mode switching buttons were set in the crutches helping the users adjust movement modes such as tuning walking speed, navigation, and interaction. The third category uses the balance control algorithm to automatically adjust the movement posture of the human-machine system, which can operate normally without structural assistance, such as the New Zealand Rex [18].

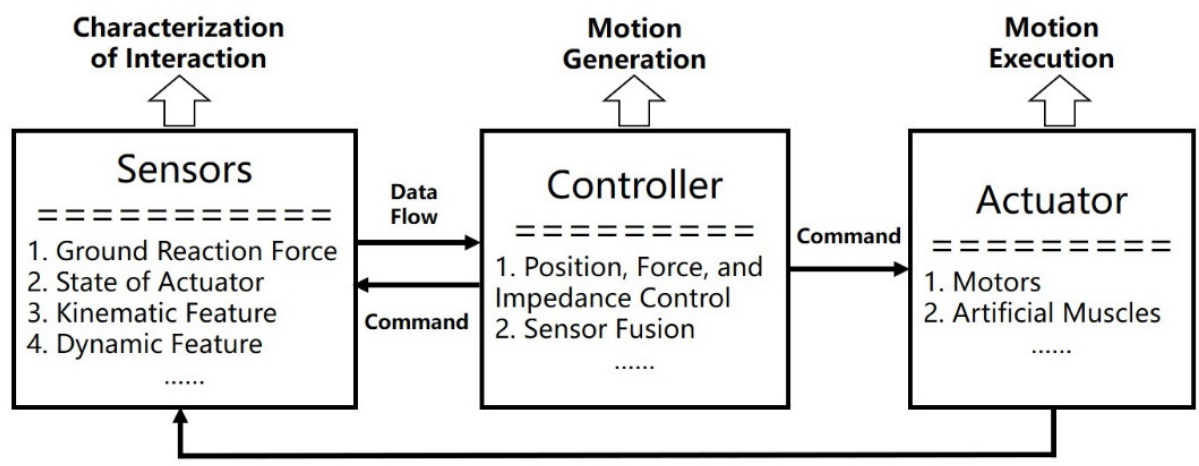

(a)

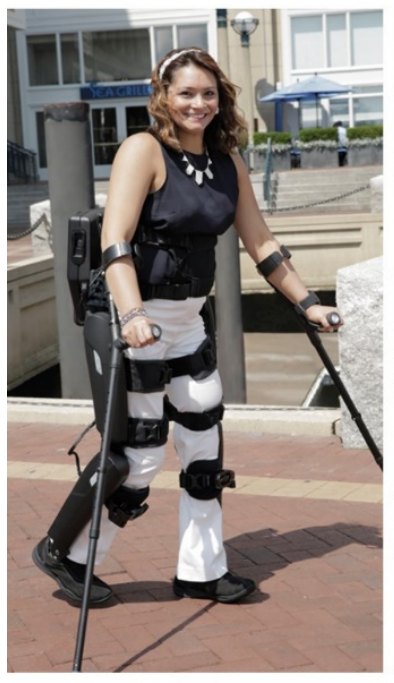

(b)

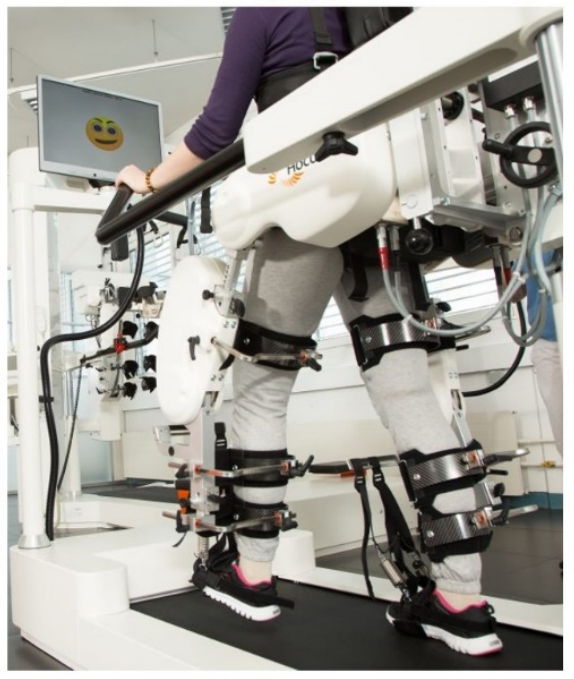

(c)

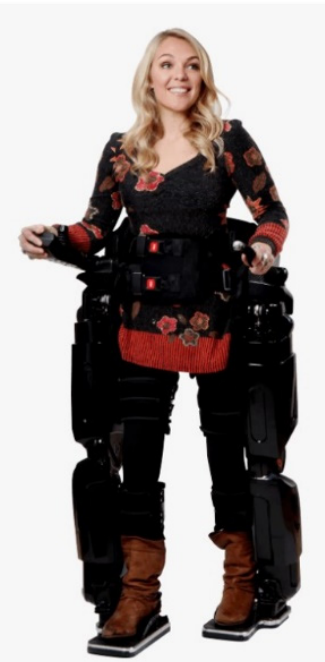

(d)

Figure 1. Overall exoskeleton plan for helping the elderly and the disabled. (a) Schematic diagram to describe the structure of exoskeletons. (b) Based on crutches, reprinted from ref. [19]; (c) Based on the platform, reprinted from ref. [17]; (d) Based on the self-balance design, reprinted from ref. [18].

In terms of active freedom configuration, the existing exoskeletons also showed different characteristics, and the summary of the existing exoskeletons is shown in Table 1. The working form of the rehabilitation exoskeletons were divided into treadmill based and over-ground. The treadmill-based exoskeletons constructed a specific trajectory in space, and the patients' legs were constrained [17]. The over-ground exoskeletons usually allowed the patients to walk on the ground $[18,19]$. Motors were still the common actuators to 
drive the motion of the exoskeleton, which were easily controlled based on the developed algorithms. The devices were designed based on the level of losing mobility. Most of the exoskeletons were targeted to the hip joints and could assist the patient to walk based on balance control. Some exoskeletons introduced crutches to avoid a tumble. However, there is still a lacking of standard validation methods to confirm the effectiveness of the exoskeletons. Some systems drive a single joint such as the knee and ankle, and the wearer often participates in a fixed posture to complete daily physical activities such as walking. In order to enable the exoskeleton to assist patients with basic gait and active hip and knee, such as Indego of Parker Hannifin Corporation [20-23], ROBIN of Korea Industrial Technology Institute of Parker Hannifin [24,25] and MINDWALKER of Delft Polytechnic University in the Netherlands. In addition [26], a few systems set multiple active joint mobilities to achieve self-balance or motor flexibility. For example, Rex of Rex Bionics, New Zealand and ATLAS 2020 [27], developed by the Spanish National Research Council, have 10 active degrees of freedom.

Table 1. Summary of existing exoskeletons and their related technical details (treadmill-based exoskeletons: The man-machine system operates on the treadmill. Over-ground: The man-machine system can operate on the ground).

\begin{tabular}{cccccc}
\hline Devices & Working Form & Actuator & Control Strategies & $\begin{array}{c}\text { Target Parts of } \\
\text { Human }\end{array}$ & $\begin{array}{c}\text { Keywords of } \\
\text { Validation Methods }\end{array}$ \\
\hline Lokomat [17] & $\begin{array}{c}\text { Treadmill based } \\
\text { exoskeleton }\end{array}$ & Motor & Position and impedance & Hip and knee & EM activity \\
\hline ALEX III [18] & Over-ground & Motor & Balance and impedance & Hip, knee and ankle & $\begin{array}{c}\text { Reshape walking } \\
\text { ability }\end{array}$ \\
\hline ReWalk [19] & Over-ground & Motor & Force and impedance & Hip and knee & Walking assistance \\
\hline Indego [23] & Over-ground & Motor & $\begin{array}{c}\text { Position and } \\
\text { force control }\end{array}$ & Hip and knee & Walking assistance \\
\hline Mindwalker [26] & Over-ground & SEA-motor & $\begin{array}{c}\text { Electroencephalogram } \\
\text { (EEG)-based } \\
\text { position control }\end{array}$ & Hip, knee and ankle & Reshape walking \\
ability
\end{tabular}

The wearable form of the rehabilitation exoskeletons guarantees the exoskeletons can assist in an ergonomic way. The exoskeletons must be designed based on the distribution of the humanoid characteristics such as muscle distribution, tendon-based transmission, and skeleton-based support. The position of the actuators should be placed along with human joints. The passive exoskeletons applied in military and industry fields showed great development in ergonomic design. Unlike the unpowered exoskeletons, the external energy should be introduced into the man-machine system because the rehabilitation exoskeletons are targeted to reshape or maintain the mobility of the people with moving dysfunction. Therefore, the rehabilitation exoskeletons should be powered exoskeletons, including actuators, sensors, and control methods. In our surveyed literature, the motors were the most traditional actuators used in rehabilitation systems, which have been developed for decades. Some novel actuators were introduced into the rehabilitation exoskeletons, such as PM and SMA, inspired by their bionic characteristics. 


\section{Actuation}

The joint actuators belong to the execution part of the exoskeleton movement, delivering the desired power to achieve the auxiliary movement. The moving performance was determined by key characteristics such as the power effect, composition shape, and response speed of the actuators. In terms of the current technology of the actuators of exoskeletons for the elderly and the disabled, it can be divided into three aspects motor drive, air pressure drive, and functional electric stimulation based on surveyed papers.

Motor-driven exoskeleton drives the system joints by a straight or rotating motor. Most rehabilitation training equipment with compact structure and fast response was driven by electric motors [33-37], as illustrated in Figure 2b. Meanwhile, the structure of the rehabilitation exoskeletons was bulky because of the big batteries and motors. Galle et al. [29] proposed a powered ankle-foot exoskeleton to reduce the metabolic cost which is driven by pneumatic artificial muscle, as shown in Figure $2 \mathrm{~b}$. Timing control was optimized and implemented, and the experimental results showed a $21 \%$ reduction in metabolic cost. However, prolonged rehabilitation training causes muscle fatigue, such as in the US Vanderbilt system [38] (Figure 2c). Similar to the PM-actuated exoskeletons, the hydraulic exoskeletons depended on the pressure supplies [28]. The electrohydraulic actuator included a motor, gear pump, and antagonistic installed cylinders [39]. The cylinders were controlled by servo valves and powered by combustion engines or electric motors.

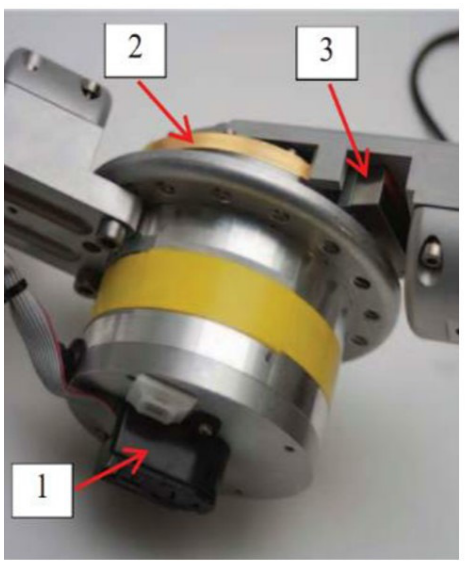

(a)

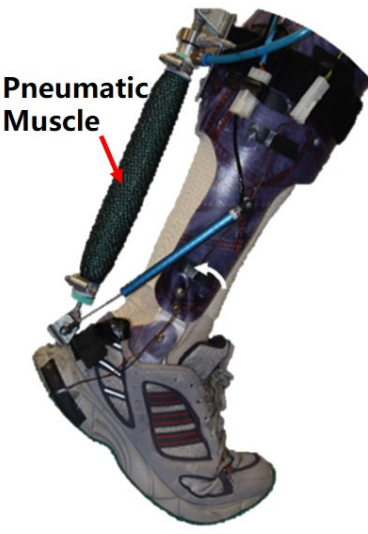

(b)

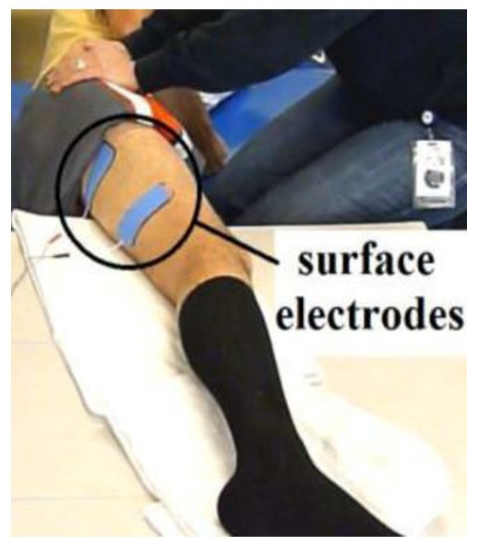

(c)

Figure 2. Exoskeleton's actuators. (a) Motor drive, adapted from ref. [33]; (b) Air pressure drive reprinted from ref. [29]; (c) Self muscle drive, reprinted from ref. [40].

In addition, new driving solutions for joint assistance are also being explored and developed. Chinese Academy of Sciences applies magnetic rheological actuator to robot rehabilitation system, which can act as a brake or clutch according to the working state of the system (human activity mode/manual activation mode) for energy consumption saving [41]. The University of Carlos III introduced the design, test, and analysis of SMA drives under various configurations and explained the feasibility of the method in soft robots and light exoskeletons [42].

The electric motors were still the most used actuators for the rehabilitation exoskeletons. Generally, the motors increase the torque by decreasing the rotation speed by the reduction boxes. That is how the electric motors were limited by requiring transmission elements to convert their high-speed, low-torque output features to low-speed and hightorque features [30]. The rehabilitation exoskeletons could provide a powerful force to lift users' body and keep balance. However, the rehabilitation exoskeletons were of large volume because of the motors, reducers, and batteries which made the system bulky and nonflexible. Therefore, there was a tradeoff between the flexible system and powerful output force. For the rehabilitation process, the movements of rehabilitation were achieved 
slowly to guarantee safety during training. It implied that the motors were suited to assist people with slow speed, which was appropriate for the disabled and the elderly.

The PMs were studied for decades from modelling, design, and control $[43,44]$. The PMs were compliant actuators mimicking human muscles, which were lightweight, had a high power-to-weight ratio, and were compliant [45]. However, there was an inevitable hysteresis between the inflation and deflation process. The hydraulic actuators were selected to drive exoskeletons because of their high-specific power [39], high-force output [28], wide control bandwidth, smooth actuation [46] etc. However, a significant limitation of the pneumatic and hydraulic actuators was the dependence on non-portable pressure supplies. Both the pumps and air compressors were too heavy and large to carry. Their applications were limited to the platform-based rehabilitation fields with no or low portability.

The other novel actuators were proposed and applied to the rehabilitation system. The SMA-actuated soft exoskeletons achieved finger motions. Due to the limited scale of the output force, novel actuators were suitable for precise rehabilitation with a small motion range. There is still a long road to transfer the novel actuators from lab to prototype.

\section{Motion Intention Perception}

Essentially, every person has a unique gait pattern, and it is inaccurate to set a fixed gait pattern [38]. Therefore, it is necessary to percept human motion to provide feedback to the exoskeleton system. Human motion intention recognition is involved in obtaining manmachine interaction and state information, data fusion algorithm to achieve the purpose of human motion, or even predict the human motion based on multiply sensors.

According to the difference in intention information acquisition mode, it can be divided into three intention perception methods based on motion signal, biological signal and mixed man-machine hybrid signal [38]. The motion signals described kinematic and dynamic characteristics such as motion acceleration, walking speed, joint angles etc., which can be measured by the gyros or accelerators. The biological signals represented the physiological information such as muscle fatigue, neural activation, etc., which can be measured by EMG, EEG, etc. The man-machine hybrid signals described the interaction forces.

The first method had been widely used in typical exoskeletal systems such as the LOPES [47] American eLEGs [48] through conventional sensors distributed in man-machine connections or system motor parts, such as an inertial measurement unit mounted on the limb, a contact force sensor in insoles. The second method could effectively reduce the hysteresis of intention perception based on extracting and processing EEG or myography data. For example, the University of Houston used non-invasive brain-computer interface technology to control the Neuro Rex exoskeleton in real-time, explain the wearer's intention through EEG signals and finally achieve the goal of assisting paraplegic patients to complete walking independently [31]. The HAL exoskeleton developed by the University of Tsukuba in Japan can detect and obtain electrical signals generated by muscle movement on the skin surface, which was processed as input to the system control [32]. The third method comprehensively considers the advantages and disadvantages of the above two methods and establishes a man-machine sensor network to comprehensively utilize biological and motion signals. The high reliability and low latency of intention perception have now become one of the focuses of research on exoskeleton technology.

A single sensing data can only reflect limited information of the man-machine interaction process. It requires the fusion processing of multimodal information of different sources, different levels and different manifestations to ensure the speed and accuracy of intention perception. For data fusion algorithms, according to the difference of data processing levels, it can be divided into data level, feature level, and decision level fusion. More common methods include D-S evidence theory, artificial neural network, adaptive weighted average, Bayesian estimation, fuzzy set theory, etc. For example, Northwestern Industrial University has achieved data fusion of EEG and EMG through D-S (Dempster/Shafer) evidence theory and backpropagation neural network [49]. The integration 
of the data collected by the three sensors improves the recognition accuracy of various motion modes.

Human motion information has been drawing researchers' attention from the aspects of the portable and wearable form, high accuracy, and low latency. Fortunately, the motion sensors can be manufactured into tiny types based on the current semi-conductor development. However, the accuracy of the motion recognition was still limited. The most popular physiological information was represented by EEG and EMG, depicting the command from the brain and execution from muscles [31,32]. Moreover, there were no non-invasive sensors with a high signal-noise ratio measuring the intention information [50]. The invasive sensors showed great potential in improving signal quality, but it is still unclear whether the invasive sensors interfere with normal human motion. MINDWALKER combined the EMG and EEG to extract the motion features to improve the accuracy [26,51,52].

Besides, motion intention could be obtained by the kinematics parameters. Indego [23] introduced inertia measurement units (IMU) to recognize gait patterns. Then, they tuned the center of pressure to track the desired movements. Peruzzi et al. [53] implemented gait evaluation based on multiple IMUs. Integrating was conducted to obtain the velocity and displacement. However, the IMUs-based motion detection would introduce inevitable errors when conducting integration. Wang et al. [54,55] implemented zero velocity state detection by judging the difference between the forward acceleration measured by the accelerator and the forward acceleration derived by the differential of angular velocity measured by gyros.

The most efficient sensors with a high signal-noise ratio and low latency represented the motion behind the human, which introduced inevitable latency of the man-machine system. Motion prediction based on kinematic and dynamic information could solve the problem essentially. It is still feasible to use the current sensors to conduct perception during rehabilitation because the rehabilitation process was usually slow-speed, and the latency of the sensors was acceptable in the slow process of rehabilitation.

\section{Control Methods}

The exoskeleton compliant control strategy is based on the result of intention perception. Controlling the joints to assist the human body in accordance with the wearer's motion intention or the rehabilitation physician's plan was key to ensure that the system generated the desired motion and produced auxiliary effects. Li et al. sorted the control strategies for lower limb rehabilitation exoskeletons with eight categories [56]. At present, common control algorithms for helping the elderly and the disabled mainly include gait trajectory planning, impedance/guide control, biological signal-based control algorithm, etc.

The trajectory planning control was usually used to perform movement tasks when humans lost the motor ability completely and conducted passive rehabilitation at the early stage of damage [57]. In the gait trajectory planning algorithm, the exoskeleton joints were controlled to produce periodic motions according to the pre-designed path, which simulated the gait of humans completing daily activities achieving the coordination of human and machine actions. The reference movement trajectory can be set in a variety of ways. Firstly, the gait trajectory playback strategy that directly uses healthy human gait parameters was widely used in rehabilitation medical exoskeleton. Systems such as WPAL $[58,59]$ in Japan and Mina $[60,61]$ in the United States can collect gait data of normal wearers and reproduce the movement process when assisting patients. Secondly, a mathematical model-based gait trajectory generation method can also be employed to calculate the required motion parameters through related theories. Rex from New Zealand generated a gait based on the ZMP model so that the system had self-balancing ability. ATLAS in Spain planned the corresponding motion trajectory based on the inverted pendulum model and calculated the key parameters such as step length and step height required to complete the desired gait [62].

Furthermore, to activate the muscle participation in the rehabilitation process and achieve compliant interaction torque and voluntary muscle torque, the impedance/admittance model 
was established to realize the mixed control of the force and position of the joint motion. The impedance control could provide assistance that is proportional to the difference between the human limb and the given trajectory [63,64]. McGill University in Canada designed a new adaptive impedance control strategy, which combined backstepping control, time delay estimation, and interference observer, improving the effect of passive assisted rehabilitation training [65]. The University of Twente in the Netherlands had designed and verified the admittance controller on the LOPES II exoskeleton, which could generate the gait trajectory of the impaired based on the healthy leg [66].

The most classic biology-based control methods were based on EMG and EEG [57]. Both of them control the exoskeletons based on the direct motion intention $[67,68]$. The control algorithm based on biological information analyzed the control input required for the movement of the exoskeleton on the basis of collecting and analyzing the bioelectric signal of the human body. The Italian Institute of Technology combined the Hill muscle model and EMG signals to estimate the driving torque required for the knee joint to complete the exercise in real-time [69]. The University of Michigan in the United States used an adaptive gain proportional EMG controller for ankle joint assistance, relying on dynamic gain to map the wearer's muscle activity to actuation control signals. The experimental trials showed that the system significantly enhanced ankle strength and reduced metabolic consumption [70]. EEG-based control is manipulating the exoskeletons based on the braincomputer interface (BCI). Evidence has shown that a patient with tetraplegia could be able to control an exoskeleton by using BCI [71]. Vouga et al. [72] enabled a monkey wearing an exoskeleton to track the cursor on a screen based on continuous regression methods. EEG parsing has been the hot research for decades, and they usually resorted to a black box model. EEG has shown great potential in controlling rehabilitation exoskeletons [73].

The interaction control theory has been developed for a long time, and it has been rather mature for the rehabilitation exoskeletons during one rehabilitation process. There was no need to demand the real-time performance of the control methods because the rehabilitation process was usually reduced to a slow process [9]. However, there was lacking rehabilitation strategy control which usually was made by the doctors. The rehabilitation strategy is to set the rehabilitation control with different groups of parameters related to users' status. The optimization methods should be implemented to select the best parameters based on the judgement of the rehabilitation stage.

\section{Validation of the Rehabilitation Exoskeleton}

Quantitative evaluation of the auxiliary effect of the exoskeleton was necessary to test and optimize the system. The evaluation indicators need to be determined according to the requirements of rehabilitation training. The efficiency evaluation of rehabilitation exoskeletons can be divided into task-based evaluation, kinematic and kinetics evaluation, and interaction evaluation. In task-based evaluation, walking speed and walking distance are direct indicators of the training results, and the corresponding data can be obtained through the 5 min walking test (5MWT) [9], 6 min walking test (6MWT), 10 m walking test (10MWT) [74], and timed up and go (TUG). Besides, endurance [75], versatility [76], and max speed [77] were used to evaluate the performance of the rehabilitation exoskeletons under specific tasks.

The validation methods for rehabilitation exoskeletons focuses on sensors used for biomechanics and energetics measurements. In general, kinematic and dynamic measurement was used to evaluate the flexibility of the rehabilitation exoskeletons and to predict energy expenditure indirectly. The most popular kinematic parameters were used to validate the exoskeletons were joint angular trajectories, range of motion (ROM), speed, and COM position [9]. Joint torque output [78], peak power [79], and maximal torque [80] were used to test the validation of the proposed exoskeletons. Metabolic cost measurement represented how much energy was saved by the rehabilitation exoskeletons. The EMG signal represented the activity of the muscle, which can be used to describe the fatigue of the muscles [74]. Kinematic parameters describe the changes of displacement in linear or 
angular position and their derivatives, such as linear velocity, linear acceleration, angular velocity, and angular acceleration. They can be obtained by the camera-based recognizing and wearable recognizing system. Kinetics aims to study forces that affect human motion. These forces can change the linear or angular motions. Force data can be obtained directly by using force and torque sensors. GRF is the representation of the human body's impact on the ground measured by force plates, which can be used to analyze the force provided by exoskeletons. The energy for human motions comes from the chemical energy by digesting food, and it flows in three directions: entropy, maintenance, and muscle energy. The energy of metabolic cost is part of muscle energy, and it can be measured indirectly by recording respiratory flow, respiratory flow rate, heart rate, muscle activity, etc.

Comfort reflected the subjective sense of patient interaction with the device. Generally, we collected the feedback about comfort based on the questionnaire. The strategies of online detection of physiological data such as heart rate and oxygen consumption can also be used to intuitively reflect the physiological state of the human body. Besides, the ergonomic parameters determined the matching performance when humans wore the exoskeletons, which represented the effectiveness of the design [9]. However, the current evaluation methods were good at confirming the effectiveness of the exoskeletons, but they failed to confirm the effectiveness of the rehabilitation process. Clinically, doctors adjust the rehabilitation process based on the score-based evaluation methods, which is currently the golden standard [81]. The multi-information collected by the sensors should be introduced into the evaluation process to confirm the rehabilitation stage.

\section{Discussion and Conclusions}

At present, countries all over the world have achieved considerable research results concerningexoskeleton technology for rehabilitation medical treatment [9]. Prototypes and commercial products with different forms and functions are emerging, bringing new ways to help the rehabilitation of the elderly and the disabled. However, in terms of the current technical conditions, it is still facing serious challenges to realize the comprehensive promotion of the exoskeleton in the social rehabilitation service system.

1. The matching performance between the exoskeletons and the human body is significantly low. The exoskeleton system with more active degrees of freedom has better flexibility, but complex structural composition and hardware lines affect the overall performance of the system. The most popular ergonomic indicators were human-robot relative position, interface displacements, anthropometric database percentiles, and adaptability to different height ranges [82]. The joints of the human body and exoskeleton have obvious rotation centers misalignment during movement, which will reduce man-machine interaction. The coupling system may be deformed and misaligned during the interaction, which may reduce the power-assisted effect. Problems similar to the above are widespread in existing systems and severely disrupt ergonomics. To make the wearable exoskeletons more comfort, the unpowered exoskeletons inspired the novel design of rehabilitation exoskeletons. The materials and manufacturing methods for lower limb exoskeletons are important because they guarantee a safe and ergonomically comfortable interface with the human $[83,84]$.

2. Sensor-based motion feedback is the basis of exoskeleton controlling and rehabilitation [56]. The joint angle and interaction torque were the frequently used feedback in most studies. The joint angle can be used to describe the difference between the given trajectory and output and calculate the force by joint angle deviation [85], the impedance by derivation of the ankle joint [86]. The interaction torque was usually used to generate real-time trajectory [87] and provided reference to correct the trajectory [88]. The recognition and prediction of human movement intention are not accurate enough. The motion intention is estimated by the mechanical signal obtained by the sensor; although the result is reliable and stable, there is a large hysteresis which is generated by the signal conversion and decoding process [89]. The human intention based on biological signal analysis has good timeliness, but the data is unstable, and 
the use process is cumbersome. Therefore, it is necessary to set up a steady communication pipeline between the rehabilitation exoskeletons and humans. Moreover, there were many kinds of existing data fusion algorithms such as radial basis function neural networks [90], convolutional neural networks [91], musculoskeletal model [92], etc., but motion mode recognition is often difficult to meet the requirements of safety and reliability accuracy. Previous work has proposed machine learning-based predictors based on EMG, kinetics, and kinematics to estimate the desired motion intention. More recently, several researchers have explored using teleceptive sensing of terrain to improve the prediction of desired locomotion [93]. The above difficulties are urgent problems to be solved in human intention recognition and prediction. It is feasible to combine the physical model of human motion with the motion data to achieve fast and stable intention perception [93]. The body domain network is designed to obtain the information of human body movement, physical parameters and state.

3. Lightweight and high power/weight ratios of driving units are difficult to achieve. Existing exoskeletons' actuators are often with lower power/weight ratios, and they have large volumes and mass, such as Lokomat [63] and ALEX [18], resulting in large and bloated overall structural forms. Hydraulic [39] and pneumatic actuators [11] improved the power/weight ratio but introduced non-portable pressure supplies and control difficulties. The series elastic actuators combined the performance of easy to control and the compliant features [67]. However, it is necessary to explore more effective driving forms as well as innovative design and optimization methods of high-power density driving units. A permanent magnet servo motor should be designed by using conservative optimization design methods to realize the lightweight of permanent magnet servo motor [94]. The speed closed-loop control strategy and position closed-loop control strategy should be designed to drive the permanent magnet motor to achieve high precision control.

4. The deviation between system motion control and human motion is prominent. The strong autonomy of human motion, the strong coupling of man-machine interaction, and the complexity of the system model have made it difficult for many control algorithms to achieve the goal of man-machine coordination and interaction [56]. The exoskeleton system should meet the needs of the wearer to complete all kinds of basic movements and basic movement transformation. For the passive rehabilitation process, the trajectory-based control is enough to replay the predefined trajectory [60]. But the predefined trajectory is not suitable for different individuals. Introducing human motion intention input into man-machine interaction control was an effective method to achieve more dexterous in assisting human motion [95]. Dynamic control strategy should be implemented in the rehabilitation system, and the stability should be confirmed based on real-time state detection and stability criteria. Dynamic control involved the dynamic modelling of the system, for example, a simple mass-springdamper model to characterize series elastic actuator [96], actuated dynamic model [97], and hybrid dynamic model [98]. Finally, optimization control methods [99] should be introduced to ensure the reliability and consistency of the rehabilitation.

A number of typical products, such as Lokomat [17], Rewalk [19], HAL [32], etc., have been successfully developed, and application verification has been initially carried out. However, due to the difficulty of lightweight design, weak motion intention identification ability and poor motion control, it is difficult to obtain the qualitative efficiency to improve the existing exoskeleton assistance. It does not have the technical level of system lightweight, accurate identification and smooth motion, which restricts the promotion and application of such exoskeletons. Therefore, it is urgent to study high torque density motor lightweight driving system design theory and method. The multi-mode human movement biological information decoding and transmission mechanism should be revealed [92], and a multi-source body and exoskeleton coordination movement compliant control strategy need to be established. The final goal is to solve the key scientific problems in the engineering application of the exoskeleton robot for the elderly and the disabled and 
provide the theoretical foundation and technical support for the development of wearable electromechanical systems.

Author Contributions: Conceptualization, W.D. and X.Z.; methodology, T.W. and Y.H.; validation, T.L., S.W. and J.P.F.; writing-original draft preparation, B.Z. and C.L.; writing-review and editing, T.W. and B.Z. All authors have read and agreed to the published version of the manuscript.

Funding: This work was supported in part by the National Natural Science Foundation of China under Grant U1913601, 52175033, and U21A20120, Zhejiang Provincial Natural Science Foundation of China: LZ20E050002, State Key La-boratory of Fluid Power and Mechatronic Systems (Grant No. GZKF-202101), and DongGuan Innovative Research Team Program (2020607202006).

Institutional Review Board Statement: Not applicable.

Informed Consent Statement: Not applicable.

Data Availability Statement: Not applicable.

Acknowledgments: We are grateful to Ning Zhang (Key Laboratory of Rehabilitation Technical Aids Technology and System of the Ministry of Civil Affairs, National Research Center for Rehabilitation Technical Aids, Beijing 100176, China, zhangning@nrcrta.cn) who made profound contributions for the project works.

Conflicts of Interest: The authors declare no conflict of interest.

\section{References}

1. Xie, X.-Y.; Lin, G.-Z.; Huang, Q.; Li, C.-B.; Hallett, M.; Voon, V.; Ren, R.-J.; Chen, S.-D.; Wang, G. Opinions and clinical practice of functional movement disorders: A nationwide survey of clinicians in China. BMC Neurol. 2021, 21, 435. [CrossRef]

2. $\mathrm{Xu}, \mathrm{S}$. Development Process and Legislative Suggestions Regarding Disability Welfare Rights in China. Political Theol. 2019, 20, 411-423. [CrossRef]

3. Li, N.; Yang, J.; Feng, X.; Zhang, J.; Yang, X.; Zhang, Z. A summary of 30 years' research on risk factors of stroke mortality in China. Chin. J. Behav. Med. Brain Sci. 2017, 26, 765-768.

4. Li, Z.; Singhal, A.; Wang, Y. Stroke Physician Training in China. Stroke 2017, 48, E338-E340. [CrossRef] [PubMed]

5. Spence, J.D. China Stroke Statistics 2019: A wealth of opportunities for stroke prevention. Stroke Vasc. Neurol. 2020, 5, 240-241. [CrossRef]

6. Simpson, L.A.; Eng, J.J.; Hsieh, J.T.C.; Wolfe, D.L. The health and life priorities of individuals with spinal cord injury: A systematic review. J. Neurotrauma 2012, 29, 1548-1555. [CrossRef] [PubMed]

7. Naoaki, T.; Takuya, E.; Yoshihiko, N.; Norihiko, K. Training to Improve the Landing of an Uninjured Leg in Crutch Walk Using AR Technology to Present an Obstacle. J. Robot. Mechatron. 2021, 33, 1096-1103.

8. Manuli, A.; Maggio, M.G.; Stagnitti, M.C.; Aliberti, R.; Cannavo, A.; Casella, C.; Milardi, D.; Bruschetta, A.; Naro, A.; Calabro, R.S. Is intensive gait training feasible and effective at old age? A retrospective case-control study on the use of Lokomat Free-D in patients with chronic stroke. J. Clin. Neurosci. 2021, 92, 159-164. [CrossRef]

9. Zhou, X.; Liu, G.; Han, B.; Li, H.; Zhang, L.; Liu, X. Different Prevention and Treatment Strategies for Knee Osteoarthritis (KOA) with Various Lower Limb Exoskeletons-A Comprehensive Review. Robotica 2021, 39, 1345-1367. [CrossRef]

10. Web of Science. Available online: http:/ / www.isiknowledge.com (accessed on 12 October 2020).

11. Goergen, R.; Valdiero, A.C.; Rasia, L.A.; Oberdorfer, M.; de Souza, J.P.; Goncalves, R.S. Development of a pneumatic exoskeleton robot for lower limb rehabilitation. In Proceedings of the IEEE International Conference on Rehabilitation Robotics (ICORR), Toronto, ON, Canada, 24-28 June 2019; pp. 187-192.

12. Copaci, D.; Flores, A.; Rueda, F.; Alguacil, I.; Blanco, D.; Moreno, L. Wearable Elbow Exoskeleton Actuated with Shape Memory Alloy. In Converging Clinical and Engineering Research on Neurorehabilitation II; Springer: Berlin/Heidelberg, Germany, 2019. [CrossRef]

13. Nasiri, R.; Shushtari, M.; Rouhani, H.; Arami, A. Virtual Energy Regulator: A Time-Independent Solution for Control of Lower Limb Exoskeletons. IEEE Robot. Autom. Lett. 2021, 6, 7699-7705. [CrossRef]

14. Vidal, A.F.P.; Morales, J.Y.R.; Torres, G.O.; Vazquez, F.D.S.; Rojas, A.C.; Mendoza, J.A.B.; Cerda, J.C.R. Soft Exoskeletons: Development, Requirements, and Challenges of the Last Decade. Actuators 2021, 10, 166. [CrossRef]

15. Hyakutake, K.; Morishita, T.; Saita, K.; Fukuda, H.; Abe, H.; Ogata, T.; Kamada, S. Effect of Robot-assisted Rehabilitation to Botulinum Toxin a Injection for Upper Limb Disability in Patients with Chronic Stroke: A Case Series and Systematic Review. Neurol. Med.-Chir. 2021, 62, 35-44. [CrossRef] [PubMed]

16. Zhang, B.; Liu, T.; Zhang, B.; Pecht, M.G. Recent Development of Unpowered Exoskeletons for Lower Extremity: A Survey. IEEE Access 2021, 9, 138042-138056. [CrossRef]

17. Lokomat. Available online: https://www.hocoma.com/media-center/media-images/lokomat (accessed on 10 November 2021).

18. Rex. Available online: https://www.rexbionics.com (accessed on 10 November 2021). 
19. Rewalk Personal 6.0 Exoskeleton: More Than Walking. Available online: https://rewalk.com/rewalk-personal-3 (accessed on 10 November 2021)

20. Hartigan, C.; Kandilakis, C.; Dalley, S.; Clausen, M.; Wilson, E.; Morrison, S.; Etheridge, S.; Farris, R. Mobility outcomes following five training sessions with a powered exoskeleton. Top. Spinal Cord Inj. Rehabil. 2015, 21, 93-99. [CrossRef]

21. Dalley, S.A.; Hartigan, C.; Kandilakis, C.; Farris, R.J. Increased Walking Speed and Speed Control in Exoskeleton Enabled Gait. In Proceedings of the 2018 7th IEEE International Conference on Biomedical Robotics and Biomechatronics (Biorob), Enschede, The Netherlands, 26-29 August 2018; pp. 689-694.

22. Andrew, E.; Michael, G. Supplemental stimulation improves swing phase kinematics during exoskeleton assisted gait of SCI subjects with severe muscle spasticity. Front. Neurosci. 2018, 12, 374.

23. Juszczak, M.; Gallo, E.; Bushnik, T. Examining the effects of a powered exoskeleton on quality of life and secondary impairments in people living with spinal cord injury. Top. Spinal Cord Inj. Rehabil. 2018, 24, 336-342. [CrossRef]

24. Jung, J.; Jang, I.; Riener, R.; Park, H. Walking intent detection algorithm for paraplegic patients using a robotic exoskeleton walking assistant with crutches. Int. J. Control. Autom. Syst. 2012, 10, 954-962. [CrossRef]

25. Jung, J.Y.; Heo, W.; Yang, H.; Park, H. A neural network-based gait phase classification method using sensors equipped on lower limb exoskeleton robots. Sensors 2015, 15, 27738-27759. [CrossRef]

26. Wang, S.; Wang, L.; Meijneke, C.; Van Asseldonk, E.; Hoellinger, T.; Cheron, G.; Ivanenko, Y.; La Scaleia, V.; Sylos-Labini, F.; Molinari, M. Design and control of the MINDWALKER exoskeleton. IEEE Trans. Neural Syst. Rehabil. Eng. 2015, 23, 277-286. [CrossRef]

27. Sanz-Merodio, D.; Puyuelo, G.; Ganguly, A.; Garces, E.; Garcia, E. EXOtrainer project clinical evaluation of gait training with exokeleton in children with spinal muscular atrophy. In Advances in Robotics Research: From Lab to Market; Springer: Berlin/Heidelberg, Germany, 2020.

28. Zoss, A.; Kazerooni, H.; Chu, A. On the Mechanical Design of the Berkeley Lowerextremity Exoskeleton (BLEEX). In Proceedings of the IEEE/RSJ International Conference on Intelligent Robots and Systems, Edmonton, AB, Canada, 2-6 August 2005; pp. 3465-3472.

29. Galle, S.; Malcolm, P.; Collins, S.H.; Clercq, D.D. Reducing the metabolic cost of walking with an ankle exoskeleton: Interaction between actuation timing and power. J. Neuroeng. Rehabil. 2017, 14, 35. [CrossRef]

30. Veale, A.J.; Xie, S.Q. Towards compliant and wearable robotic orthoses: A review of current and emerging actuator technologies Med. Eng. Phys. 2016, 38, 317-325. [CrossRef] [PubMed]

31. Contreras-Vidal, J.L.; Grossman, R.G. NeuroRex: A Clinical Neural Interface Roadmap for EEG-Based Brain Machine Interfaces to a Lower Body Robotic Exoskeleton. In Proceedings of the 2013 35th Annual International Conference of the IEEE Engineering in Medicine and Biology Society, Osaka, Japan, 3-7 July 2013; pp. 1579-1582.

32. Kadone, H.; Kubota, S.; Abe, T.; Noguchi, H.; Miura, K.; Koda, M.; Shimizu, Y.; Hada, Y.; Sankai, Y.; Suzuki, K.; et al. Mucular activity modulation during post-operative walking with Hybrid Assistive Limb (HAL) in a patient with thoracic myelopathy due to ossification of posterior longitudinal ligament: A case report. Front. Neurol. 2020, 11, 102. [CrossRef] [PubMed]

33. Raj, A.K.; Neuhaus, P.D.; Moucheboeuf, A.M.; Noorden, J.H.; Lecoutre, D.V. Mina: A sensorimotor robotic orthosis for mobility assistance. J. Robot. 2011, 2, 284352.1-284352.8. [CrossRef]

34. Pransky, J. The Pransky interview: Russ Angold; Co-founder and president of Ekso(TM) labs. Ind. Robot. 2014, 41, 329-334. [CrossRef]

35. Suzuki, N.; Soga, T.; Izumi, R.; Toyoshima, M.; Shibasaki, M.; Sato, I.; Kudo, Y.; Aoki, M.; Kato, M. Hybrid Assistive Limb (R) for sporadic inclusion body myositis: A case series. J. Clin. Neurosci. 2020, 81, 92-94. [CrossRef]

36. Nankaku, M.; Tanaka, H.; Ikeguchi, R.; Kikuchi, T.; Miyamoto, S.; Matsuda, S. Effects of walking distance over robot-assisted training on walking ability in chronic stroke patients. J. Clin. Neurosci. 2020, 81, 279-283. [CrossRef]

37. Kuroda, M.; Nakagawa, S.; Mutsuzaki, H.; Mataki, Y.; Yoshikawa, K.; Takahashi, K.; Nakayama, T.; Iwasaki, N. Robot-assisted gait training using a very small-sized Hybrid Assistive Limb (R) for pediatric cerebral palsy: A case report. Brain Dev. 2020, 42, 468-472. [CrossRef]

38. Chen, G.; Chan, C.K.; Guo, Z.; Yu, H. A review of lower extremity assistive robotic exoskeletons in rehabilitation therapy. Crit. Rev. Biomed. Eng. 2013, 41, 343-363. [CrossRef]

39. Saito, Y.; Kikuchi, K.; Negoto, H.; Oshima, T.; Haneyoshi, T. Development of Externally Powered Lower Limb Orthosis with Bilateral-Servo Actuator. In Proceedings of the IEEE 9th International Conference on Rehabilitation Robotics, Chicago, IL, USA, 28 June-1 July 2005; pp. 394-399.

40. Ha, K.H.; Quintero, H.A.; Farris, R.J.; Goldfarb, M. Enhancing Stance Phase Propulsion during Level Walking by Combining FES with a Powered Exoskeleton for Persons with Paraplegia. In Proceedings of the 2012 Annual International Conference of the IEEE Engineering in Medicine and Biology Society, San Diego, CA, USA, 28 August-1 September 2012; pp. 344-347.

41. Xu, J.; Li, Y.; Xu, L.; Peng, C.; Chen, S.; Liu, J.; Xu, C.; Cheng, G.; Xu, H.; Liu, Y.; et al. A multi-mode rehabilitation robot with magnetorheological actuators based on human motion intention estimation. IEEE Trans. Neural Syst. Rehabil. Eng. 2019, 27, 2216-2228. [CrossRef]

42. Copaci, D.; Blanco, D.; Moreno, L.E. Flexible shape-memory alloy-based actuator: Mechanical design optimization according to application. Actuators 2019, 8, 63. [CrossRef] 
43. Yamamoto, K.; Ishii, M.; Hyodo, K.; Yoshimitsu, T.; Matsuo, T. Development ofpower assisting suit (miniaturization of supply system to realize wearable suit). JSME Int. J. Ser. C 2003, 46, 923-930. [CrossRef]

44. Caldwell, D.G.; Tsagarakis, N.G.; Kousidou, S.; Costa, N.; Sarakoglou, I. "Soft" exoskeletons for upper and lower body rehabilitation-Design, control and testing. Int. J. Hum. Robot. 2007, 4, 549-573. [CrossRef]

45. Carvalho, A.; Navin, K.P.; Desai, V. Design and characterization of a pneumatic muscle actuator with novel end-fittings for medical assistive applications. Sens. Actuators A Phys. 2021, 331, 112877. [CrossRef]

46. Otten, A.; Voort, C.; Stienen, A.; Aarts, R.; van Asseldonk, E.; Kooij, H.V.D. LIMPACT: A hydraulically powered self-aligning upper limb exoskeleton. IEEE Trans. Mechatron. 2015, 20, 2285-2298. [CrossRef]

47. Zhao, G.; Sharbafi, M.; Vlutters, M.; van Asseldonk, E.; Seyfarth, A. Template model inspired leg force feedback based control can assist human walking. In Proceedings of the 2017 International Conference on Rehabilitation Robotics, London, UK, 17-20 July 2017; pp. 473-478.

48. Strausser, K.A.; Swift, T.A.; Zoss, A.B.; Kazerooni, H.; Bennett, B.C. Mobile Exoskeleton for Spinal Cord Injury: Development and Testing. In Proceedings of the Asme Dynamic Systems and Control Conference and Bath/Asme Symposium on Fluid Power and Motion Control, Bath, UK, 14-16 September 2012; pp. 419-425.

49. Choi, J.; Na, B.; Jung, P.-G.; Rha, D.-W.; Kong, K. WalkON suit: A medalist in the powered exoskeleton race of cybathlon. 2016 IEEE Robot. Autom. Mag. 2017, 24, 75-86. [CrossRef]

50. Lenzi, T.; De Rossi, S.M.M.; Vitiello, N.; Carrozza, M.C. Intention-based EMG control for powered exoskeletons. IEEE Trans. Biomed. Eng. 2012, 59, 2180-2190. [CrossRef] [PubMed]

51. Athanasiou, A.; Lithari, C.; Kalogianni, K.; Klados, M.A.; Bamidis, P.D. Source detection and functional connectivity of the sensorimotor cortex during actual and imaginary limb movement: A preliminary study on the implementation of eCoonectome in motor imagery protocols. Adv. Hum. Comput. Interact. 2012, 2012. Available online: https:/ /www.researchgate.net/publication/ 258381811 (accessed on 12 October 2020). [CrossRef]

52. Cheron, G.; Duvinage, M.; De Saedeleer, C.; Castermans, T.; Bengoetxea, A.; Petieau, M.; Seetharaman, K.; Hoellinger, T.; Dan, B.; Dutoit, T.; et al. From spinal central pattern generators to cortical network: Integrated BCI for walking rehabilitation. Neural Plast. 2012, 2012, 375148. [CrossRef] [PubMed]

53. Peruzzi, A.; Della Croce, U.; Cereatti, A. Estimation of stride length in level walking using an inertial measurement unit attached to the foot: A validation of the zero velocity assumption during stance. J. Biomech. 2011, 44, 1991-1994. [CrossRef] [PubMed]

54. Wang, L.; Sun, Y.; Li, Q.; Liu, T. Estimation of step length and gait asymmetry using wearable inertial sensors. IEEE Sens. J. 2018, 18, 3844-3851. [CrossRef]

55. Wang, L.; Sun, Y.; Li, Q.; Liu, T. Two shank-mounted imus-based gait analysis and classification for neurological disease patients. IEEE Robot. Autom. Lett. 2020, 5, 1970-1976. [CrossRef]

56. Li, W.Z.; Cao, G.Z.; Zhu, A.B. Review on Control Strategies for Lower Limb Rehabilitation Exoskeletons. IEEE Access 2021, 9 , 123040-123060. [CrossRef]

57. Wang, H.; Mu, T.; Li, H.; Zhang, X. Research on Surface EMG Based Accurate Perception Method for Exoskeleton Robot Control. In Proceedings of the 2015 IEEE International Conference on Cyber Technology in Automation, Control and Intelligent Systems (IEEE-CYBER 2015), Shenyang, China, 9-12 June 2015; pp. 1900-1905.

58. Yatsuya, K.; Hirano, S.; Saitoh, E.; Tanabe, S.; Tanaka, H.; Eguchi, M.; Katoh, M.; Shimizu, Y.; Uno, A.; Kagaya, H. Comparison of energy efficiency between Wearable Power-Assist Locomotor (WPAL) and two types of knee-ankle-foot orthoses with a medial single hip joint (MSH-KAFO). J. Spinal Cord Med. 2018, 41, 48-54. [CrossRef] [PubMed]

59. Tanabe, S.; Koyama, S.; Saitoh, E.; Hirano, S.; Yatsuya, K.; Tsunoda, T.; Katoh, M.; Gotoh, T.; Furumoto, A. Clinical feasibility of gait training with a robotic exoskeleton (WPAL) in an individual with both incomplete cervical and complete thoracic spinal cord injury: A case study. Neurorehabilitation 2017, 41, 85-95. [CrossRef] [PubMed]

60. Griffin, R.; Cobb, T.; Craig, T.; Daniel, M.; van Dijk, N.; Gines, J.; Kramer, K.; Shah, S.; Siebinga, O.; Smith, J.; et al. Stepping forward with exoskeletons team IHMC's design and approach in the 2016 Cybathlon. IEEE Robot. Autom. Mag. 2017, 24, 66-74. [CrossRef]

61. Mummolo, C.; Peng, W.; Agarwal, S.; Griffin, R.; Neuhaus, P.; Kim, J. Stability of Mina v2 for robot-assisted balance and locomotion. Front. Neurorobotics 2018, 12, 16. [CrossRef]

62. Sanz-Merodio, D.; Sancho, J.; Perez, M.; Garcia, E. Control architecture of the ATLAS 2020 lower-limb active orthosis. Adv. Coop. Robot. 2017, 860-868.

63. Riener, R.; Lünenburger, L.; Jezernik, S.; Anderschitz, M.; Colombo, G.; Dietz, V. Patient-cooperative strategies for robot-aided treadmill training: First experimental results. IEEE Trans. Neural. Syst. Rehabil. Eng. 2005, 13, 380-394. [CrossRef]

64. Veneman, J.F.; Kruidhof, R.; Hekman, E.E.G.; Ekkelenkamp, R.; Van Asseldonk, E.H.F.; van der Kooij, H. Design and evaluation of the LOPES exoskeleton robot for interactive gait rehabilitation. IEEE Trans. Neural. Syst. Rehabil. Eng. 2007, 15, 379-386. [CrossRef]

65. Brahmi, B.; Driscoll, M.; El Bojairami, I.K.; Saad, M.; Brahmi, A. Novel adaptive impedance control for exoskeleton robot for rehabilitation using a nonlinear time-delay disturbance observer. ISA Trans. 2021, 108, 381-392. [CrossRef]

66. Meuleman, J.; van Asseldonk, E.; van Oort, G.; Rietman, H.; van der Kooij, H. LOPES II—Design and evaluation of an admittance controlled gait training robot with shadow-leg approach. IEEE Trans. Neural Syst. Rehabil. Eng. 2016, 24, 352-363. [CrossRef] [PubMed] 
67. Gu, Y.; Yang, D.; Huang, Q.; Yang, W.; Liu, H. Robust EMG pattern recognition in the presence of confounding factors: Features, classifiers and adaptive learning. Expert Syst. Appl. 2018, 96, 208-217. [CrossRef]

68. Lazarou, I.; Nikolopoulos, S.; Petrantonakis, P.C.; Kompatsiaris, I.; Tsolaki, M. EEG-based brain-computer interfaces for communication and rehabilitation of people with motor impairment: A novel approach of the 21st century. Front. Hum. Neurosci. 2018, 12, 14. [CrossRef] [PubMed]

69. Karavas, N.; Ajoudani, A.; Tsagarakis, N.; Saglia, J.; Bicchi, A.; Robotics, J.; Systems, A. Tele-impedance based assistive control for a compliant knee exoskeleton. Robot. Auton. Syst. 2015, 73, 78-90. [CrossRef]

70. Koller, J.R.; Jacobs, D.A.; Ferris, D.P.; Remy, C.D. Learning to walk with an adaptive gain proportional myoelectric controller for a robotic ankle exoskeleton. J. Neuroeng. Rehabil. 2015, 12, 97. [CrossRef]

71. Benabid, A.L.; Costecalde, T.; Eliseyev, A.; Charvet, G. An exoskeleton controlled by an epidural wireless brain-machine interface in a tetraplegic patient: A proof of concept demonstration. Lancet Neurol. 2019, 18, 1112-1122. [CrossRef]

72. Vouga, T.; Zhuang, K.Z.; Olivier, J.; Lebedev, M.A.; Nicolelis, M.A.L.; Bouri, M.; Bleuler, H. EXiO-A brain-controlled lower limb exoskeleton for rhesus macaques. IEEE Trans. Neural Syst. Rehabil. Eng. 2017, 25, 131-141. [CrossRef]

73. Gwin, J.T.; Ferris, D.P. An EEG-based study of discrere isometric and isotonic human lower limb muscle contractions. J. Neuroeng. Rehabil. 2012, 9, 35. [CrossRef]

74. Hong, E.; Gorman, P.H.; Forrest, G.F.; Asselin, P.K.; Knezevic, S.; Scott, W.; Wojciehowski, S.B.; Kornfeld, S.; Spungen, A.M Mobility skills with exoskeletal-assisted walking in persons with SCI: Results from three center randomized clinical trial. Front. Robot. AI 2020, 7, 93. [CrossRef]

75. Norris, J.A.; Granata, K.P.; Mitros, M.R.; Byrne, E.M.; Marsh, A.P. Effect of augmented plantarflexion power on preferred walking speed and economy in young and older adults. Gait Posture 2007, 25, 620-627. [CrossRef]

76. Arazpour, M.; Bani, M.A.; Hutchins, S.W. Reciprocal gait orthoses and powered gait orthoses for walking by spinal cord injury patients. Prosthet. Orthot. Int. 2013, 37, 14-21. [CrossRef] [PubMed]

77. Lerner, Z.F.; Damiano, D.L.; Bulea, T.C.A. Robotic Exoskeleton to Treat Crouch Gait from Cerebral Palsy: Initial Kinematic and Neuromuscular Evaluation. In Proceedings of the 2016 38th Annual International Conference of the IEEE Engineering in Medicine and Biology Society (EMBC), Orlando, FL, USA, 16-20 August 2016; pp. 2214-2217.

78. Aguirre-Ollinger, G.; Colgate, J.E.; Peshkin, M.A.; Goswami, A. Inertia compensation control of a one-degree-of-freedom exoskeleton for lower-limb assistance: Initial experiments. IEEE Trans. Neural Syst. Rehabil. Eng. 2012, 20, 68-77. [CrossRef] [PubMed]

79. Li, W.; Lemaire, E.D.; Baddour, N. Design and Evaluation of a Modularized Ankle-Foot Orthosis with Quick Release Mechanism. In Proceedings of the 2020 42nd Annual International Conference of the IEEE Engineering in Medicine \& Biology Society (EMBC), Montreal, QC, Canada, 20-24 July 2020; pp. 4831-4834.

80. Shao, Y.; Zhang, W.; Xu, K.; Ding, X. Design of a novel compact adaptive ankle exoskeleton for walking assistance. Adv. Mech. Mach. Sci. 2019, 173, 2159-2168.

81. Tan, C.; Sun, F.; Fang, B.; Kong, T.; Zhang, W. Autoencoder-based transfer learning in brain-computer interface for rehabilitation robot. Int. J. Adv. Robot Syst. 2019, 16, 1-12. [CrossRef]

82. Elia, N.D.; Vanetti, F.; Cempini, M.; Pasquini, G.; Parri, A.; Rabuffetti, M.; Ferrarin, M.; Molino Lova, R.; Vitiello, N. Physical human-robot interaction of an active pelvis orthosis: Toward ergonomic assessment of wearable robots. J. NeuroEngineering Rehabil. 2017, 14, 29.

83. Haldane, D.W.; Casarez, C.S.; Karras, J.T.; Lee, J.; Li, C.; Pullin, A.O.; Schaler, E.W.; Yun, D.; Ota, H.; Javey, A.; et al. Fearing Integrated manufacture of exoskeletons and sensing structures for folded millirobots. J. Mech. Robot. 2015, 7, 021011. [CrossRef]

84. Yandell, M.B.; Quinlivan, B.T.; Popov, D.; Walsh, C.; Zelik, K.E. Physical interface dynamics alter how robotic exosuits augment human movement: Implications for optimizing wearable assistive devices. J. Neuroeng. Rehabil. 2017, 14, 40. [CrossRef]

85. Martínez, A.; Lawson, B.; Goldfarb, M. A controller for guiding leg movement during overground walking with a lower limb exoskeleton. IEEE Trans. Robot. 2018, 34, 183-193.

86. Nagarajan, U.; Aguirre-Ollinger, G.; Goswami, A. Integral admittance shaping: A unified framework for active exoskeleton control. Robot. Auton. Syst. 2016, 75, 310-324. [CrossRef]

87. Aguirre-Ollinger, G.; Yu, H. Omnidirectional platforms for gait training: Admittance-shaping control for enhanced mobility. J. Intell. Robot. Syst. 2021, 101, 52. [CrossRef]

88. Zhang, T.; Tran, M.; Huang, H. Admittance shaping-based assistive control of SEA-driven robotic hip exoskeleton. IEEE/ASME Trans. Mechatron. 2019, 24, 1508-1519. [CrossRef]

89. Leal-Junior, A.G.; Frizera-Neto, A.; Pontes, M.J.; Botelho, T.R. Hysteresis compensation technique applied to polymer optical fiber curvature sensor for lower limb exoskeletons. Meas. Sci. Technol. 2017, 28, 125103. [CrossRef]

90. Gui, K.; Liu, H.; Zhang, D. A practical and adaptive method to achieve EMG-based torque estimation for a robotic exoskeleton. IEEE/ASME Trans. Mechatron. 2019, 24, 483-494. [CrossRef]

91. Wang, F.; Yan, L.; Xiao, J. Recognition of the gait phase based on new deep learning algorithm using multisensor information fusion. Sens. Mater. 2019, 31, 3041-3054. [CrossRef]

92. Cardona, M.; Cena, C.E.G.; Serrano, F.; Saltaren, R. ALICE: Conceptual development of a lower limb exoskeleton robot driven by an on-board musculoskeletal simulator. Sensors 2020, 20, 789. [CrossRef] 
93. Krausz, N.E.; Hargrove, L.J. A Survey of Teleceptive Sensing for Wearable Assistive Robotic Devices. Sensors 2019, $19,5238$. [CrossRef]

94. Hussain, F.; Goecke, R.; Mohammadian, M. Exoskeleton robots for lower limb assistance: A review of materials, actuation, and manufacturing methods. Proc. Inst. Mech. Eng. Part H J. Eng. Med. 2021, 235, 1375-1385. [CrossRef]

95. Ronsse, R.; Lenzi, T.; Vitiello, N.; Koopman, B.; Van Asseldonk, E.; De Rossi, S.M.M.; Van Der Kieboom, J.; Van Der Kooij, H.; Carrozza, M.C.; Ijspeert, A.J. Oscillator-based assistance of cyclical movements: Model-based and model-free approaches. Med. Biol. Eng. Comput. 2011, 49, 1173-1185. [CrossRef]

96. Yu, H.; Huang, S.; Chen, G.; Pan, Y.; Guo, Z. Human-robot interaction control of rehabilitation robots with series elastic actuators. IEEE Trans. Robot. 2015, 31, 1089-1100. [CrossRef]

97. Liang, C.; Hsiao, T. Admittance control of powered exoskeletons based on joint torque estimation. IEEE Access 2020, 8, 94404-94414. [CrossRef]

98. Lv, G.; Zhu, H.; Gregg, R.D. On the design and control of highly backdrivable lower-limb exoskeletons: A discussion of past and ongoing work. IEEE Control. Syst. 2018, 38, 88-113. [CrossRef] [PubMed]

99. Rose, L.; Bazzocchi, M.C.F.; Nejat, G. End-to-End Deep Reinforcement Learning for Exoskeleton Control. In Proceedings of the IEEE International Conference on Systems, Man, and Cybernetics, Toronto, ON, Canada, 11-14 October 2020; pp. $4294-4301$. 